Review

\title{
The Porter-Whitesides Discrepancy: Revisiting Odd-Even Effects in Wetting Properties of n-Alkanethiolate SAMs
}

\author{
Zhengjia Wang ${ }^{1}$, Jiahao Chen ${ }^{1,2}$, Stephanie Oyola-Reynoso ${ }^{1}$ and Martin Thuo ${ }^{1,2,3, *}$
}

1 Department of Materials Science and Engineering, Iowa State University, 2220 Hoover Hall, Ames, IA 50011, USA; E-Mails: zhengjia@iastate.edu (Z.W.); jiahao@iastate.edu (J.C.); so1@iastate.edu (S.O.-R.)

2 Micro-Electronic Research Center, Iowa State University, 133 Applied Sciences Complex I, 1925 Scholl Road, Ames, IA 50011, USA

3 Biopolymer and Biocomposites Research Team, Center for Bioplastics and Biocomposites, Iowa State University, 1041 Food Sciences Building, Ames, IA 50011, USA

* Author to whom correspondence should be addressed; E-Mail: mthuo@iastate.edu; Tel.: +1-515-294-8581.

Academic Editor: James Tsoi

Received: 30 September 2015 / Accepted: 10 December 2015 / Published: 21 December 2015

\begin{abstract}
This review discusses the Porter-Whitesides discrepancy in wetting properties of n-alkanethiolate self-assembled monolayers (SAMs). About 25 years ago, Whitesides and coworker failed to observe any odd-even effect in wetting, however, Porter and his coworker did, albeit in select cases. Most previous studies agreed with Whitesides' results, suggesting the absence of the odd-even effect in hydrophobicity of n-alkanethiolate SAMs. Recent reports have, however, found the odd-even effect in hydrophobicity of n-alkanethiolate SAMs on smooth substrates, indicating that hydrophobicity, and analogous interfacial properties, of n-alkanethiolate SAMs significantly depends on the properties of substrate. Unfortunately, the Whitesides and Porter papers do not report on the quality of the surfaces used. Based on recent work, we inferred that the original discrepancy between Whitesides and Porter can be attributed to the quality of the surface. Odd-even effect of SAMs in charge transport, capacitance, friction, and SAM structure are also discussed in this review to inform the general discussion. The discrepancy between Porter's group and Whitesides' group could be due to surface roughness, morphology, oxidation, and adventitious contaminants.
\end{abstract}


Keywords: self-assembled monolayer; odd-even effect; roughness; hydrophobicity

\section{Introduction}

The study of organic thin films began about 200 years ago, when Franklin discovered, in 1774, the calming effect of oil on water surface [1]. However, systematic study of self-assembled monolayer was not carried out until the last century. Over the past 25 years, tremendous growth in the field of self-assembled monolayers (SAMs) has been witnessed, especially in synthetic sophistication and characterization. In 1946, the preparation of a monomolecular layer by adsorption (self-assembly) of a surfactant onto a clean metal surface was reported by Zisman [2]. This seminal work by Zisman did not draw wide interest, since the potential of self-assembled monolayers was not recognized. Kuhn and co-workers applied this method to form a monolayer of chlorosilane derivative on glass, which ignited an interest in chemisorbed SAMs [3]. Nuzzo and Allara showed that SAMs of alkanethiolates on gold can be prepared by adsorption of bifunctional, organic disulfide molecules from dilute solutions [4]. SAMs are molecular assemblies formed spontaneously by adsorption of molecular constituents from solution or from the gas phase on surfaces. This self-assembly process is a mechanism by which disordered small building units spontaneously arrange into large, ordered phases [5]. Many self-assembled systems have been investigated, with monolayers of alkanethiolates on gold or silver being the most studied SAM systems to date [6-15].

SAMs offer unique opportunities to understand fundamental fields, such as self-organization, structure-property relationships, and interfacial phenomena. Hydrocarbon molecules, due to simplicity in structure, are widely studied in the field of SAMs. Components of hydrocarbon molecule adsorbed on metal surface are schematically shown (Figure 1a). An alkanethiol SAM usually containing three parts: (i) The head group (S) that binds to the substrate when SAMs are prepared, the molecules are chemisorbed on the surfaces via an interaction between the head group and the substrate; (ii) The spacer chain (typically made up of methylene groups, $\left(\mathrm{CH}_{2}\right)_{n}$ ) that connects head group and terminal functional group. Favorable secondary interaction between the methylene hydrogens leads to better packing and ordered assemblies; (iii) The terminal functional group provides a platform where any desired group can be introduced to alter the chemical nature of the interface. The ability to symmetrically alter the moieties in the head and tail groups makes SAMs excellent systems for fundamental understanding of phenomena dependent on competing intermolecular, molecular-substrates, and, molecule-solvent interactions; for example friction, wetting, adhesion, lubrication, and corrosion [5-7,15-20].

The overall structure of SAMs involves the interplay of head group, substrate and intermolecular interactions. For example, when n-alkanethiolate SAMs are fabricated on gold, the arrangement of the sulfur atoms on the surface defines the free space (footprint) available for the molecules, which then organize to optimize intermolecular interactions within geometric constraints. These interactions are governed by the substrate topology, head-group hybridization, and, molecular constituents [15]. Alkylthiolates SAMs adsorb on $\mathrm{Au}(111)$ have a $(\sqrt{3} \times \sqrt{3}) \mathrm{R} 30^{\circ}$ structure where the molecules preferably adsorb at a three-fold hollow site of the $\mathrm{Au}(111)$ surface, whereas on $\operatorname{Ag}(111)$ a commensurate $(\sqrt{7} \times \sqrt{7}) \mathrm{R} 19.1^{\circ}$ structure [11], which consists of three molecules per surface unit cell, with two of the molecules adsorbed onto hollow sites and one onto a top site. As shown in Figure 1b, 
the alkanethiol molecules in the SAMs are oriented with an average tilt angle of $\sim 10^{\circ}$ to $\sim 30^{\circ}$, depending on the metal substrates. Figure 1c schematically shows three basic type of SAMs formed on the surface: (i) well-ordered, crystalline alkanethiolate SAM; (ii) defective SAM with domain boundary, a by-product of the assembly process; and, (iii) poorly formed SAM whose hydrocarbon chains are not fully extended under growth conditions and/or different substrates quality. This type of poor assembly can be due to use of very dilute solution or not allowing the assembly process to equilibrate, i.e., go to completion.

The SAMs interfaces can be controlled by varying the terminal functional group because this group is the predominantly exposed to the monolayer interface, which significantly effects surface chemistry, and can be altered through the synthesis of the precursor alkanethiols. A small change in the tail group can lead to completely different physical and chemical properties of the surface. These terminal groups include; $-\mathrm{CH}_{3},-\mathrm{OH},-\mathrm{COOH}$, or ferrocene among others (Figure 1d), where the choice is dependent on desired surface properties.

a.

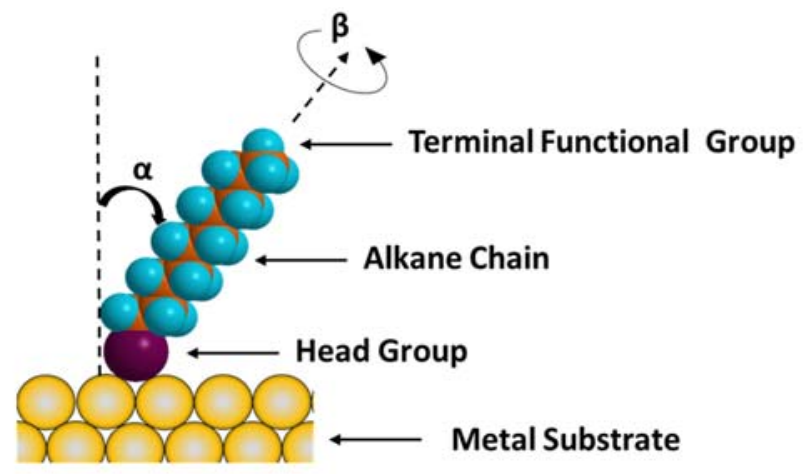

b.

$\alpha \cong 30^{\circ}$
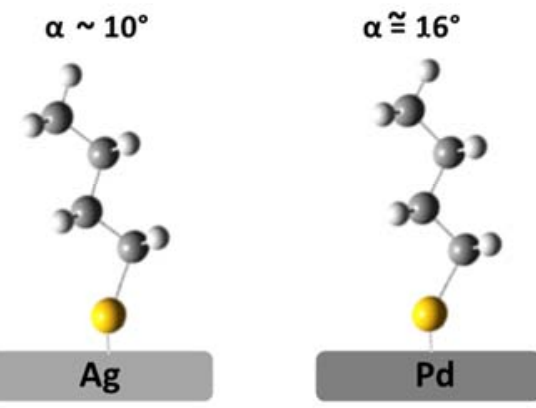

c.
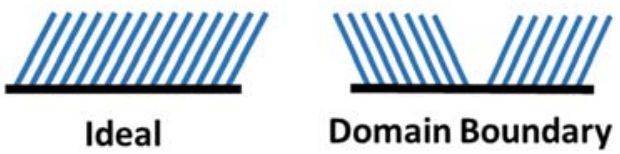

d.<smiles>CC(C)C(C)C(C)C(C)O</smiles><smiles>CC(C)(C)C(=O)O</smiles>

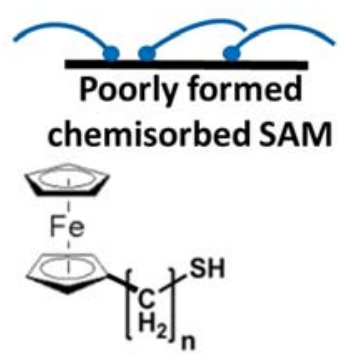

Figure 1. (a) Schematic diagram of an ideal, single-crystalline self-assembled molecule of alkanethiolates supported on a metal substrate. The anatomy and characteristics of the SAM are highlighted; (b) The tilt angles $(\alpha)$ is defined with respect to the surface normal on different metal surfaces, approximately $30^{\circ}$ on gold, $10^{\circ}$ on silver and $16^{\circ}$ on palladium; (c) Schematic illustration of SAMs forming dynamics; (d) Different terminal functional groups. 
The most extensively studied of SAMs are derived from the adsorption of n-alkanethiols on gold, and silver $[5,6,10,21,22]$. The well-defined monolayer contributes to the material surface modification, due to its useful and highly alterable chemical functionalities at the exposed interface. SAMs provide a convenient, flexible, and simple system with which to tailor the interfacial properties of metals, metal oxides, and semiconductors.

\section{Hydrophobicity of SAMs}

The interfacial properties of SAMs are significant in modification of solid surfaces based on the fact that interfacial structures determine surface properties and functions of a material. Wettability is uniquely valuable in characterizing organic surfaces derived from SAMs on metal substrates. A significant issue is the detailed relationships between molecular features at surface, such as orientation and roughness, and wetting. The wettability of SAMs has been extensively studied on Au and Ag substrates, by measuring the contact angle of probe liquids on the organic monolayers [10,21]. The wettability of these organic monolayers is strongly associated with the static and/or advancing contact angle of the SAMs and probe liquids. Generally, it is dependent on the exposure of the top-most functional groups, the orientation and dipole moment of the terminal group, and the geometry of the alkyl chain spacer.

This review discusses the hydrophobicity of n-alkanethiolate SAMs, as captured in the contact angle formed between a water droplet and the SAMs on either Au or Ag. This simple property of SAMs has been assumed to be a well-understood property but review of the literatures indicates that there were misunderstandings from the begin that remained unsolved for one and two decades. There is, therefore, need to recalibrate and clarify the presence or absence of the so-called odd-even effect in hydrophobicity of simple n-alkanethiolate SAMs.

\subsection{The Original Studies}

In 1991, Laibinis et al. (Whitesides' group) reported the wetting properties of n-alkanethiols $\left(\mathrm{CH}_{3}\left(\mathrm{CH}_{2}\right)_{n} \mathrm{SH}\right)$ monolayers adsorbed on copper, silver and gold with water and hexadecane (HD) [10]. They measured the static advancing and receding contact angles of various probe liquids on monolayers prepared by the immersion of substrates in solutions of n-alkanethiols of various length (Figure 2a(i,ii),b(i,ii)). The results showed the wetting behaviors on the silver and gold were similar, with the contact angles of both liquids being significantly lower when $n \leq 8$ than when $n \geq 11$. They discussed the results based on the effect of SAMs structure on wetting. These seminal works, and others $[8,10,12,23,24]$, showed that monolayers on silver and gold were more reproducible than on copper in part due to morphological changes that occur due to oxidation and/or subsequent desorption of the alkanethiol. Therefore, most studies of interface structure-property relationships in wetting of monolayers has focused on SAMs formed on silver and gold. The wettability of monolayers formed on silver and gold exhibit a common increase in hydrophobicity with increasing chain length. The lower hydrophobicities of monolayers prepared from shorter alkanethiols $(n<9)$ is thought to be due to disorder in the shorter chain molecules and, potentially, interaction of the probe liquid with methylene (alkyl chain) instead of methylalthough coulombic interactions between the dipole of the probe liquid and the now proximal oxidized metal surface (due to bond formation) can also be envisioned. The value of the contact angle tend to plateau off with longer n-alkyl chains, and this was attributed to increased crystallinity of the SAMs $[25,26]$. 
The SAM formation process, however, leads to a polycrystalline surface especially due to defects like domain boundaries and pin holes, or substrate defects like step edges and grain boundaries. It seems interesting, given the different surface structures that Laibinis et al. [10] did not observe a difference in wettability between odd- and even- numbered alkanethiols while, on the other hand, Walczak et al. [21] only observed it for a few molecules in a homologous series.
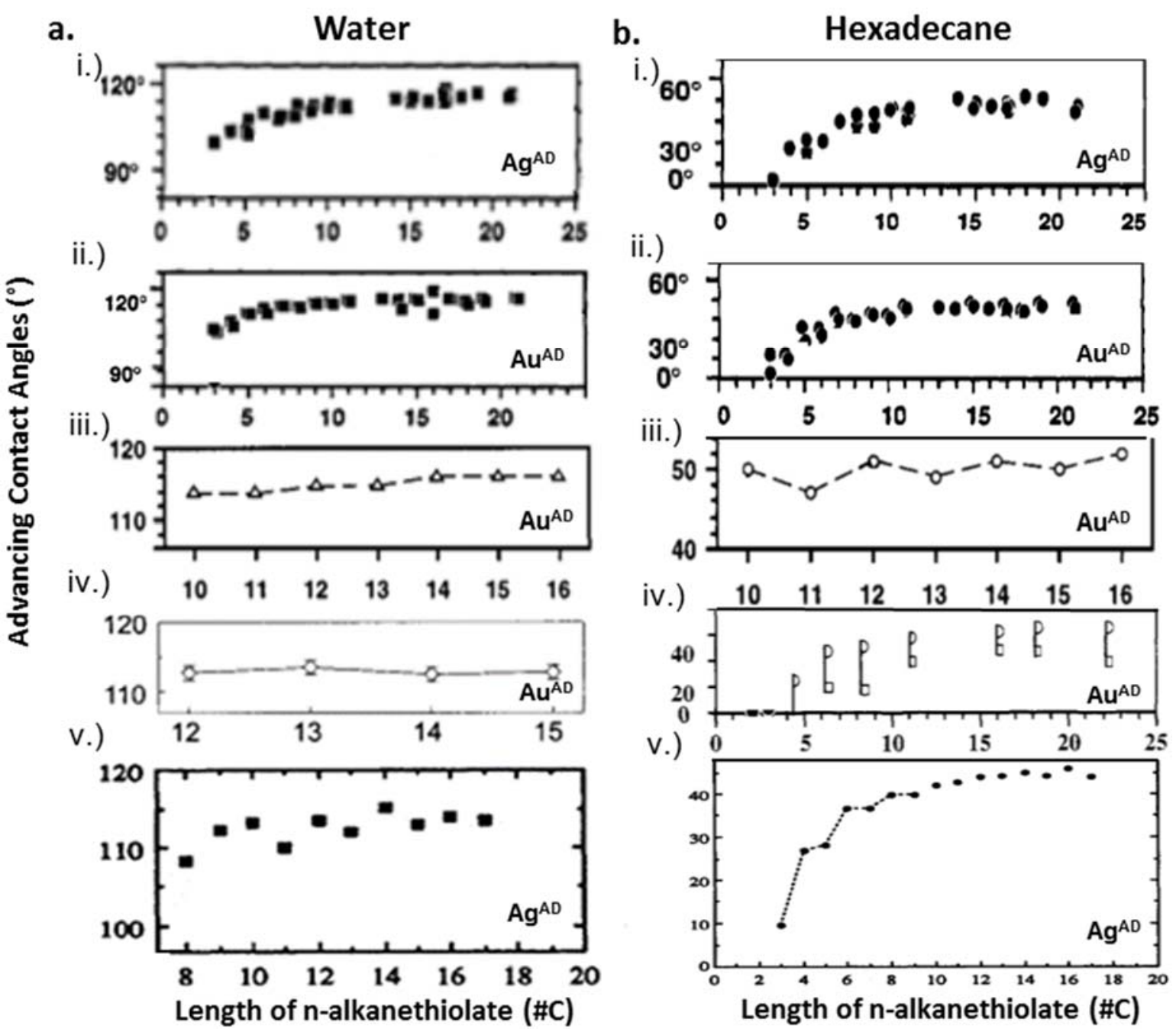

Figure 2. (a) Hydrophobicity of n-alkanethiolate SAMs as captured through values of advancing contact angles formed between the SAM and a drop of water as reported by (i,ii) Whitesides and co-workers [10]; (iii) Graupe et al. and Miura et al. [8]; (iv) Colorado and Lee et al. [27]; and (v) Porter and co-workers [21] on Ag or Au; (b) wettability of n-alkanethiolate SAMs as captured through values of advancing contact angles formed between the SAM and a drop of hexadecane as reported by (i,ii) Whitesides and co-workers [10]; (iii) Graupe et al. and Miura et al. [8]; (iv) Biebuyck et al. [22]; and (v) Porter and co-workers [21] on Ag or Au. All previous studies were performed on "as-deposited" surfaces. Graphs are reprinted with permission from (i,ii) [10], Copyright 1991 American Chemical Society; (iii) [8], Copyright 1999 American Chemical Society; (iv) [25], Copyright 2001 American Chemical Society; [22], Copyright 1994 American Chemical Society; and (v) [21], Copyright 1991 American Chemical Society. 
Earlier in the year, however, Walczak et al. (Porter's group) gave discrepant observations [21]. They characterized the structure and properties of $n$-alkanethiols adsorbed on evaporated silver films by wetting, ellipsometry, and infrared spectroscopy. The comparison of such results between Whitesides' group and Porter's group indicates general agreements between the sets of data, but shows differences for monolayers derived from shorter n-alkanethiols. Whitesides' group did not observe an odd-even effect in the wettability of Ag-S- $\left(\mathrm{CH}_{2}\right)_{n} \mathrm{CH}_{3}$, by water $(n=10-16)$, while Porter's group did. A major conflict in all these early studies is that no report was given on the quality of surfaces used (roughness) nor was there a report on the reproducibility (number of repeats). State of the art in film preparation, however, allows us to assume the surface used had a root mean square (RMS) roughness $>1 \mathrm{~nm}$. Follow-up reports seemed to concur more with the results of Whitesides' group that no odd-even oscillation was observed in the values of contact angle [8,10,27]. Whitesides' group did not observe an odd-even effect in SAM-HD contact angles. Porter's group, however, did observe an odd-even effect in SAM-HD contact angles but did not offer explanation for its disappearance at $n \geq 8$. Laibinis offers insight to the challenge in understanding the discrepancy and argues that: "Porter et al. also use corresponding odd-even variations in wettability for $n=4-8$ (that we do not observe) as complementary evidence. We suspect most (if not all) of the differences between our work and that of Porter et al. to be due to adventitious (and perhaps contaminant promoted) oxidation of their evaporated films of silver prior to adsorption of the alkanethiol, and to the sensitivity of this system to surface oxidation when one uses shorter $(n \leq 6) n$-alkanethiols. We note that both papers have had difficulty preparing high-quality monolayers from shorter chain alkanethiols. We cannot, however, exclude some contribution to differences in the procedures used to prepare the silver films, and to resulting differences in grain size, preferred orientation, and surface topology."

In short, Laibinis et al. [10] argue that the discrepancy in their results is due to experimental errors, an inference that seemed to be supported by following works except for the case of HD where the odd-even effect was often observed. The difficulties in understanding wetting property of SAMs demonstrate the challenges that technology can impose on scientific advancement in such a case, and theoretical study of complex systems can offer insights into the material.

\subsection{Molecular Simulation of Odd-Even Effects in Wetting}

In 2005, 14 years later, Laibinis et al. performed molecular dynamics (MD) simulations to investigate the odd-even chain length dependencies in the wetting properties of SAMs of n-alkanethiols on gold with water and HD [28]. They suggested that the contact angle of HD on the SAMs depended on whether carbon number is odd or even, while contact angles of water showed no odd-even dependence. The contact angles calculated by MD simulations for nanoscopic droplets (either 256 water molecules or $60 \mathrm{HD}$ molecules localized on an n-alkanethiolate SAM on gold) were consistent with experimentally observed macroscopic trends in wettability, namely, that HD is sensitive to structural differences between odd- and even-chained SAMs while water was not. Laibinis argues that MD simulations of the interfacial contact between SAMs and water or HD indicates that the wetting properties of these probe liquids on the structure of the SAM was dependent on the chain terminus, rather than on the inner structure of the SAM. And due to the densities of water and HD, water displayed a significant depletion at the liquid/SAM interface, while no such depletion occurred for HD. They claimed this contact depletion of 
water might explain the absence of an odd-even effect in the wetting property of water on SAMs, because the water molecules did not directly contact with surface and, therefore, were not sensitive to the orientation changes of the terminal methyl groups in odd- and even-chained SAMs. In contrast, the odd-even effect in the wetting properties of HD on the odd- and even-chained SAMs were caused by the closer proximity of HD molecules to the SAM surface hence resulting in greater sensitivity to the terminal methyl group orientations in the SAMs.

The three preceding reports, are, therefore, in conflict with each other. Studies [10,21] reported in 1991 (original work) and up to a few years ago [8,22,27], did not offer a clear understanding as to whether an odd-even effect exist in the hydrophobicity of SAMs or not. Laibinis' theoretical work seems to infer that some of Porter's (HD) or Whitesides' (water) data were correct, but fails to offer a conclusive explanation that is supported by experimental data. A review of others studies in which the odd-even effect in SAMs is reported can offer insights as to whether this effect should be accepted as a basic property of SAMs.

\section{3. "Odd-Even" Effect in SAMs}

The odd-even effect in properties of SAMs is a phenomenon that has, sometimes, been observed in wetting, tunneling junctions, friction, field-effect transistors, molecular diodes, and SAM structures, among other properties. In general, an odd-even effect describes a zigzag oscillation in material structure and/or properties depending on the odd or even number of a basic unit, which is often the number of $\mathrm{CH}_{2}$ group, present in the molecules that make up the monolayer. Understanding the origin, and the role, of the odd-even effect in simple n-alkanethiolate SAMs on Au and Ag surfaces has recently gathered a lot of interests. Structure of the SAMs has been implicated to induce odd-even alterations of chemical, physical, surface, and, interfacial properties, such as chemical reactivity, electronic property, friction behavior, and electrochemical property [14]. Based on the structure of an ideal SAM, an odd-even effect in wetting or other interface dependent properties should be expected assuming that the SAM is fabricated on an atomically flat surface and molecules are in an all trans-extended conformation with no gauche rotation (Figure 3).

\subsubsection{Odd-Even in Wetting (Pre-2014)}

Interfacial properties of methyl terminated SAMs depend on the chain length (odd or even number) of alkanethiolate molecule. SAMs, having an all trans-extended methylene backbone structure, possess distinct orientations of the terminal group, dependent on whether the number of backbone methylene units is odd or even (Figure 3). The odd-even effect in the wetting property of SAMs is, however, complicated, or at least the literature is not coherent. Odd-even effects in the wetting of fluorinated SAMs on gold by glycerol, DMF (N,N-dimethylformamide), acetonitrile, and HD have been reported, but no odd-even effect has been observed on $\mathrm{CH}_{3}\left(\mathrm{CH}_{2}\right)_{n} \mathrm{~S}-\mathrm{Au}$ [8]. The lack of an odd-even effect has been attributed to the fact that a terminal $\mathrm{CF}_{3}$ group generates a strong dipole at the surface; these molecules also present an ordered array of dipoles to the contacting liquid to increase the wettability, which indicates that the wetting property depends on the exposure of the topmost functional group of the SAM. Because methyl groups and phenyl groups represent hydrocarbon moieties with distinct chemical and physical properties, a systematic investigation of the interfacial properties of a sequential 
series of phenyl-terminated SAMs provides an excellent opportunity to explore the chemical origin(s) of odd-even interfacial effects. The contact angles of SAMs of biphenyl-substituted thiols $\left(\left(\mathrm{CH}_{3}-\mathrm{C}_{6} \mathrm{H}_{4}-\right.\right.$ $\left.\mathrm{C}_{6} \mathrm{H}_{4}-\left(\mathrm{CH}_{2}\right)_{m}-\mathrm{SH}, m=1-6\right)$ exhibit a distinct odd-even effect for hexadecane and water [29]. However, a weak odd-even effect of contact angle for $\mathrm{C}_{6} \mathrm{H}_{5}-\left(\mathrm{C}_{6} \mathrm{H}_{4}\right)_{2}-\left(\mathrm{CH}_{2}\right)_{n}-\mathrm{S}-\mathrm{Au}$ monolayers has been observed when methylene iodide or nitrobenzene were used as probe liquids while a probe liquid with a small dipole moment, such as $\mathrm{H}_{2} \mathrm{O}$, did not show any odd-even effect [14]. In addition, the odd-even effect of wetting properties was also observed in $\mathrm{CH}_{3}\left(\mathrm{CH}_{2}\right)_{n} \mathrm{~S}-\mathrm{Au}$ monolayers with methylene iodide, nitrobenzene or DMF, but, similarly, no odd-even effect when the probe liquid was water [28]. All these results demonstrate that structures and properties, such as packing density and wettability of SAM, may be altered by substituting the terminal group of the self-assembled molecule, and, hence, the interfacial wetting property between liquid and organic monolayer will be different when the probe liquid is changed.

a.

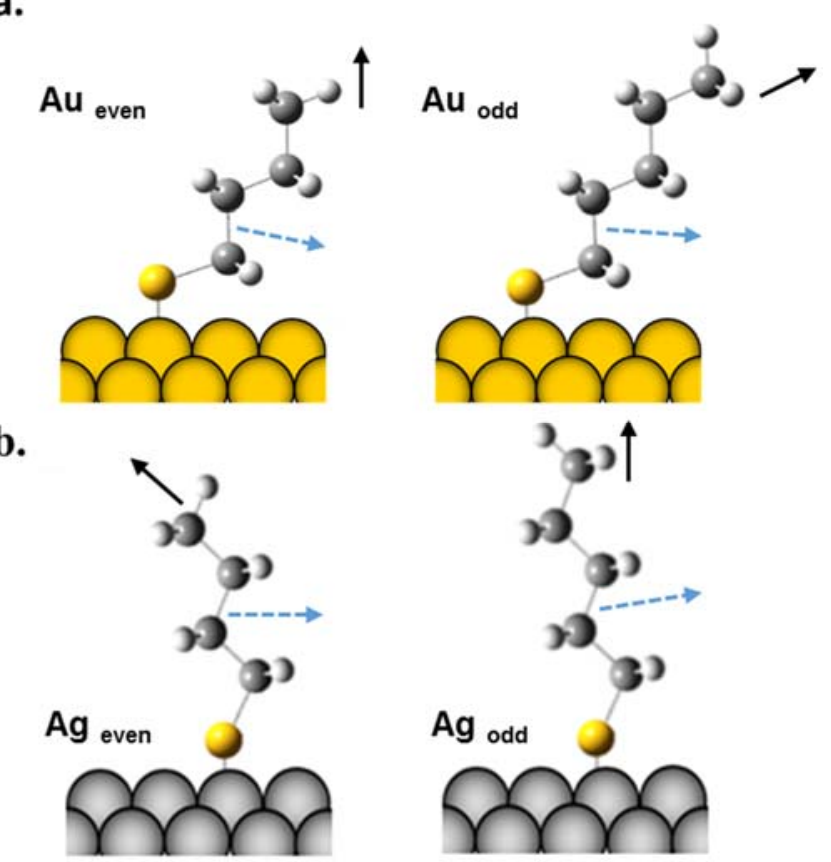

Figure 3. (a) Schematic illustration of the structural effect of the SAM tilt angle, surface dipole and orientation of the terminal moiety on $\mathrm{Au}$; (b) Schematic illustration of the structural effect of the SAM tilt angle, surface dipole (dotted arrows) and orientation of the terminal moiety (solid arrow) on Ag.

\subsubsection{Odd-Even Effect in Other SAM Properties}

\section{Odd-Even Effect in Charge Transport}

Charge transport through molecular junctions are widely studied, especially the SAM-based large area junctions. The current (or current density, $J$ ) through the junctions is usually interpreted according to the simplified Simmon's Equation (Equation (1))

$$
J=J_{0} e^{-\beta d}
$$

where $\beta$ is the tunneling decay constant, $d$ is the thickness of a SAM, and $J_{0}\left(\mathrm{~A} / \mathrm{cm}^{2}\right)$ is due to contact resistant, that is, the current density across a hypothetical SAM without any carbon chains $(d=0)$. 
The odd-even effect in charge transport across SAM-based junctions, where subtle changes in the SAMs structure (molecular length induced) lead to oscillation of electronic properties - the "odd-even" effect, are well established for SAMs fabricated on smooth surfaces. Thuo et al. reported an odd-even effect in tunneling current across $\mathrm{Ag}^{\mathrm{TS}}-\mathrm{SC}_{n} / / \mathrm{GaO}_{x} / \mathrm{EGaIn}$ junction (“"//" refers to an interface defined by physisorption) in Figure 4a, and suggested that both the SAM interface and bulk could be playing a major role in the observed oscillation of tunneling current (odd-even effect) [18]. Following work showed a larger difference in the odd-even in tunneling currents when a more polar moiety was introduced into the internal structure of the SAMs, by replacing- $\mathrm{CH}_{2} \mathrm{CH}_{2}-$ with $-\mathrm{CONH}-$ (Figure 4b) [30]. Nurbawono and coworkers suggest that the twist angle, $\gamma$, which changes with molecule chain length, and has effect on the odd-even effect of charge transport. The twist angle affects the interaction between distal hydrogen and the top electrode, and different $\gamma$ induces different interaction, which lead to an odd-even effect in tunneling barrier and, therefore, an odd-even effect in charge transport [31].
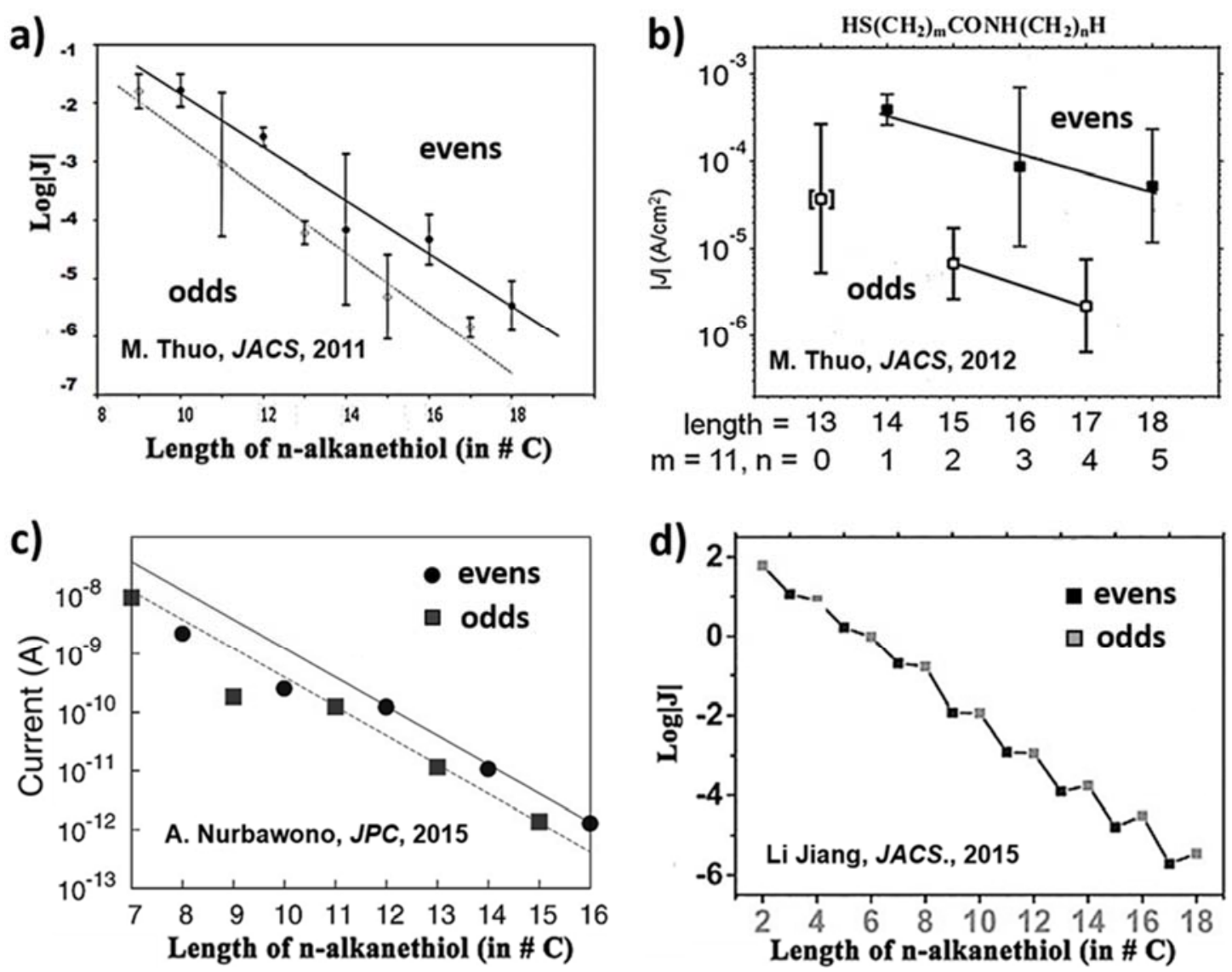

Figure 4. The odd-even effect in charge transport. (a,b) Experimental-derived odd-even effect of charge transport across alkanethiolate SAMs and SAMs with amide terminal group [18,31]; (c) theoretical study of odd-even effect of charge transport across alkanethiolate SAMs [32]; (d) study of odd-even effect in alkanethiolate SAMs with wide range analysis indicates the odd-even effect is a mixed effect of interface effect and variance of SAMs inherent properties [33]. Graphs are reprinted with permission from (a) [18], Copyright 2011 American Chemical Society; (b) [31], Copyright 2012 American Chemical Society, (c) [32], Copyright 2015 American Chemical Society; and (d) [33], Copyright 2015 American Chemical Society. 
A systematic study, reported by Nijhuis and co-workers, revealed the origin of odd-even effect in tunneling rates across alkanethiolate SAMs (Figure 4d) [32]. This study suggests that the odd-even effect is a combination of interface effect and variance of inherent properties of the SAMs. Three odd-even effects are observed in the study: (i) odd-even effect in $R_{C}$ (contact resistance, addressing the interface effect); (ii) odd-even effect in CsAm (SAMs' capacitance); and (iii) odd-even effect in RsAm (SAMs' resistance). All three components contribute to the observed odd-even effect of tunneling current.

The odd-even effect in charge tunneling is also observed in ferrocenyl-alkanethiolate $\left(\mathrm{S}\left(\mathrm{CH}_{2}\right)_{n} \mathrm{Fc}\right)$ SAMs based molecular diodes [33,34]. The ferrocene terminated alkanethiols are widely studied in charge transport as molecular diodes. In these molecules, however, a reduction in width of the tunneling barrier is only observed at forward bias, due to the fact that the highest occupied molecular orbital (HOMO) of the Fc falls between Fermi levels of both electrodes and, as such, charge can hop into the Fc units; at reserve bias, the tunneling barrier is larger since the charges cannot be injected into Fc frontier orbitals [35]. Such a difference between forward and reverse bias leads to current rectification, forming a molecular diode. An odd-even in tunneling current oscillation is observed at forward bias through $\mathrm{Ag}^{\mathrm{TS}}-\mathrm{SC}_{n} \mathrm{Fe} / / \mathrm{Ga}_{2} \mathrm{O}_{3} / \mathrm{EGaIn}$ junctions $\left(\mathrm{C}_{8}-\mathrm{C}_{14}\right)$. Similarly, a reversed odd-even effect of charge tunneling is observed in $\mathrm{Au}^{\mathrm{TS}}-\mathrm{SC}_{n} \mathrm{Fe} / / \mathrm{Ga}_{2} \mathrm{O}_{3} / \mathrm{EGaIn}$ junctions $\left(\mathrm{C}_{8}-\mathrm{C}_{14}\right)$. Nijhuis and coworkers suggest that the observed odd-even effect in tunneling current in a molecular diode is attributed to two effects, (i) the electronic effect, which includes surface dipole, work function and energy level variance between HOMO and Fermi level of electrodes, and; (ii) the supramolecular structure due to the tilting angle of the terminal Fc units [36-38].

\section{Odd-Even Effect in Capacitance}

Nijhuis and coworkers reported the observation of the odd-even effect in capacitance in n-alkanethiolate SAMs (CsAm) [32]. It is argued that the observed, large odd-even effect in capacitance is an intrinsic properties of SAMs rather than increase of effective SAMs thickness, as confirmed by estimating CsAM using Equation (2).

$$
C_{S A M}=\varepsilon_{0} \varepsilon_{r} A / d_{S A M}
$$

where $\varepsilon_{0}$ is the free space permittivity, $\varepsilon_{\mathrm{r}}$ is the dielectric constant for the SAMs, and A is the geometric contact area of junctions.

The origin of such an odd-even effect is significantly influenced by the large difference in dielectric constant for the odds ( $\left.\varepsilon_{\mathrm{r}, \mathrm{odd}}\right)$ and the evens $\left(\varepsilon_{\mathrm{r}, \mathrm{even}}\right)$, and is suggested to stem from the odd-even effect in the twist angle of the alkanethiol molecule, $\gamma[35]$.

\section{Odd-Even in Tribology}

The friction of SAMs on solid surfaces attracts considerable interest because the self-assembled layer(s) could be used as lubricants, where organized molecules adsorbed on a substrate are used as effective methods to minimize the friction and/or adhesion of moving mechanical assemblies in micro- or nanoelectromechanical devices. Reports of the odd-even effect in SAMs tribological properties are widely reported in the literature [14,39-42], from both experimental and simulation studies, especially those addressing the frictional properties attributed to the terminal groups' effect. Through 
experiments and simulations studies, the odd-even effect is, however, not dependent on the chain length of the molecule, as expected, since tribological effect are generally interface-based.

Wong et al. studied the tribology between the SAMs $\left(\mathrm{CH}_{3}\left(\mathrm{CH}_{2}\right)_{n} \mathrm{~S}-\mathrm{Au}(n=12-16)\right)$ and a bare probe tip using friction force microscopy (FFM) [16]. They observed an odd-even alternation in the friction force, depending on the odd or even number of $\mathrm{CH}_{2}$ units in the molecular chain. They summarized that the odd-even difference in the orientation of the terminal $\mathrm{CH}_{3}$ of the SAMs had a detectable influence on friction. Additionally, the overall decreasing trend of frictional force with the increase of chain length implied possibly a mechanical contribution, such as adlayer elasticity, which was associated with the increase of chain length.

Ramin et al. [43] conducted molecular dynamics simulations to study the frictional properties of alkanethiols $\mathrm{CH}_{3}\left(\mathrm{CH}_{2}\right)_{n} \mathrm{SH}(12 \leq n \leq 15)$ SAMs on $\mathrm{Au}(111)$ surfaces, under various loading and shearing conditions. They observed that the friction coefficient was dependent on the number of carbon atoms in the basic unit being either odd or even. Alkanethiols with $n=$ odd showed consistently higher friction coefficients than those with $n=$ even. Such an odd-even effect, however, seems to be independent of the sliding velocity [43]. They also studied the frictional behavior and effects of compression on structural properties of $n$-alkanethiols $(n=14,15)$ SAMs on $\mathrm{Au}(111)$ in the presence of water under different ranges of normal pressures by molecular dynamics simulation. Interesting odd-even effects in water penetration and frictional properties were revealed by simulations of one odd and one even SAM system. They observed the presence of water reduced the friction only at lower pressures; and at higher pressures, SAMs without water presence offer lower friction [44].

However, no obvious odd-even effect in the friction properties of the $\mathrm{C}_{6} \mathrm{H}_{5}\left(\mathrm{CH}_{2}\right)_{n} \mathrm{SH}$ SAMs has been reported, though the friction response of this series of phenyl ring-terminated monolayers generally decreases with increasing chain length. The reason for the absence of an odd-even effect in friction property of this phenyl SAMs remains unclear [14].

\section{Odd-Even in SAM Packing Structure}

Most of the fundamental studies for SAMs have been performed with alkanethiols; however, more recently, aromatic-terminated alkylthiols have gained interest, in part due to their electronic properties. Future application of aromatic-terminated alkylthiols requires insight in the molecular structure and how to control film structure. Heister et al. applied synchrotron-based high resolution X-ray photoelectron spectroscopy to study the influence of small variations in the molecular geometry on the biphenyl-substituted alkanethiols $\left(\mathrm{CH}_{3}-\left(\mathrm{C}_{6} \mathrm{H}_{4}\right)_{2}-\left(\mathrm{CH}_{2}\right)_{n}-\mathrm{SH}, \mathrm{BP} n, n=1-4\right)$ SAM structure and properties [45]. They identified an odd-even effect in the packing density and the tilt angle of the biphenyl moieties on the structure of SAMs on Au and Ag substrates, and revealed a number of additional odd-even effects upon variation of the number of methylene groups in the aliphatic part in the $\mathrm{BP} n$ molecule, which suggests that a BP $n$ SAM represents a strongly correlated, highly ordered molecular assembly.

Odd-even variation in the molecular structure for SAMs formed from 4,4'-terphenyl-substituted alkanethiols $\mathrm{C}_{6} \mathrm{H}_{5}\left(\mathrm{C}_{6} \mathrm{H}_{4}\right)_{2}\left(\mathrm{CH}_{2}\right)_{n} \mathrm{SH}(\mathrm{TP} n, n=1-6)$ on polycrystalline (111) gold and silver substrates has also been demonstrated based on X-ray photoelectron spectroscopy (XPS), high-resolution XPS, infrared reflection absorption spectroscopy, near-edge X-ray absorption fine structure spectroscopy, and scanning tunneling microscopy (STM) investigations to delineate the relationship between molecular 
structure and film structure [46,47]. An odd-even effect of TPn films (except $\mathrm{TP}_{2}$ ) has been reported regarding both molecular orientation and packing density. The packing density for the even-numbered TPn SAMs is $25 \%$ lower than that for the odd numbered TPn SAMs [47]. This is schematically illustrated (Figure 5), which indicates the head group-substrate bond in SAMs of alkanethiols is an important parameter affecting the packing density and molecular orientation of the SAM constituents. Shaporenko et al. assumed "an $s p^{3}$ hybridization of the thiolate head groups on Au (a substrate-S-C angle of $\approx 104^{\circ}$ ) and a rigid aliphatic linker in all-trans conformation (as shown by IRRAS), one gets a less tilted orientation of the terphenyl moieties in TPn/Au for $n=$ odd and a more tilted orientation for $n=$ even. Contrary, in the case of an sp hybridization of the thiolate head group on Ag (a substrate-S-C angle of $\approx 180^{\circ}$ ), a less tilted orientation of the terphenyl moieties in TPn/Ag is realized for an even $n$ and a less tilted one for an odd $n$. The true substrate- $S-C$ angles in the TPn SAMs are probably not exactly equal to $\approx 104^{\circ}$ and $\approx 180^{\circ}$, but rather the respective bending potentials depend on the deviation of the metal-S-C angle from these optimal values and hence contribute to the overall balance of the structural forces" [46].

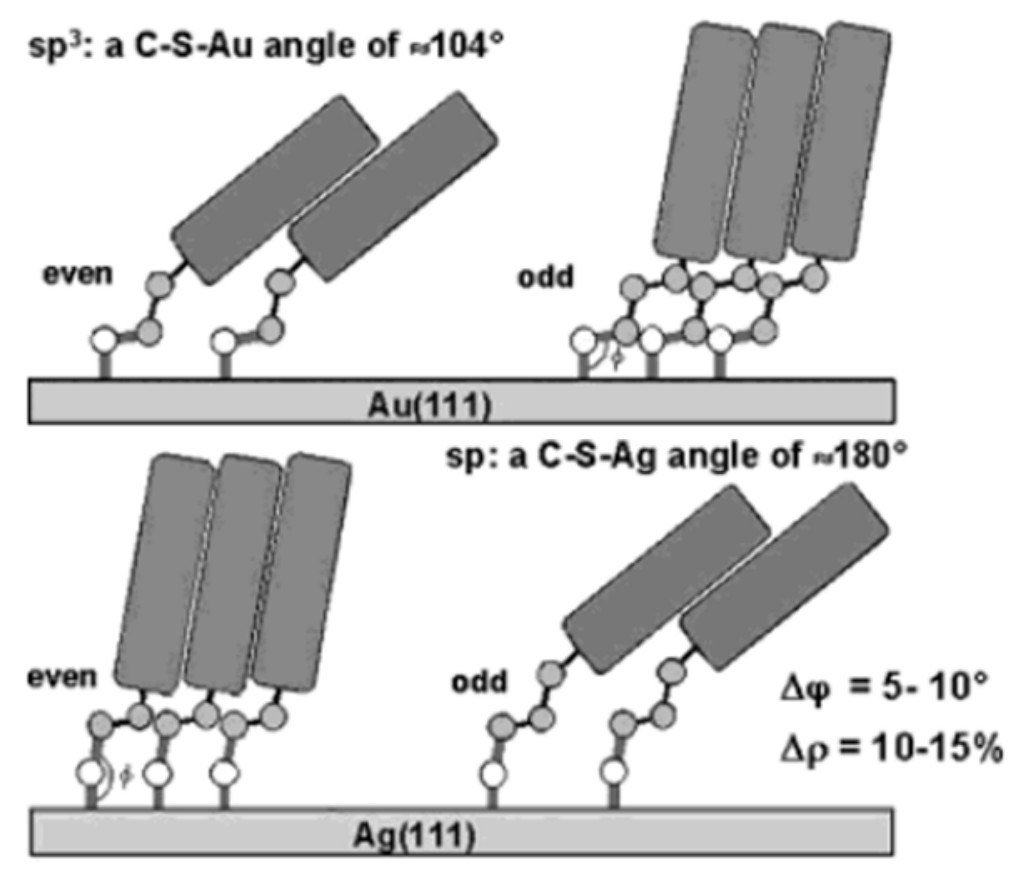

Figure 5. Schematic illustration of the orientation and packing structure of the $\mathrm{TP}_{\mathrm{n}} \mathrm{SAMs}$ on $\mathrm{Au}$ and Ag, Graph is reprinted with permission from [46], Copyright 2004 American Chemical Society.

Ramin et al. have extensively studied effect of temperature on structure of alkanethiols SAMs ( $4 \leq n \leq 22)$ on $\mathrm{Au}(111)$ surfaces using molecular dynamics simulations [48]. They reported clear dependence of the structural properties, on both the number of carbon atoms, and on $n$ being odd or even. Meanwhile, they observed that a gradual decrease in the tilt angle occurred for all alkanethiols when the temperature increased from 300 to $420 \mathrm{~K}$. Order and disorder phase transitions occurred at a certain temperature, which showed an enhancement of $\sim 67-100{ }^{\circ} \mathrm{C}$ over the melting point of the corresponding n-alkanethiol. This enhancement depended on the number of carbon atoms, and was larger for $n=$ odd [48]. 


\section{Substrates}

\subsection{Substrates Preparation}

Smooth metal substrates are usually used to fabricate SAMs. Types of substrates can be planar surfaces (glass or silicon slabs with thin metal films, metal foils, single crystals) or highly curved nanostructures (colloids, nanocrystals, nanorods). Planar substrates are widely used for characterizing the relationships between structure and property of SAMs due to easy in prepare and compatibility with a number of surface analysis and characterization techniques. There are four main methods to prepare the metal substrates (Figure 6), viz; (a) chemical mechanical polishing (CMP); (b) physical vapor deposition (PVD); (c) template stripping; and (d) annealing-assisted template stripping [11]. CMP and PVD are common method to make flat metal surface but with limited flatness [49]. For over two decades, template stripping has been the method of choice to make ultra-flat surface with low roughness $(\sim 0.4 \mathrm{~nm})$ [49], see Section 3.2. The annealing-assisted template stripping generally involve two parts, an annealing step and a template stripping step. The annealing process aims to enlarge the grains and lower the roughness, receiving more desirable ultra-flat surfaces. The most common planar substrates for SAMs are thin films of metal supported on silicon wafers, glass, or mica. These substrates are easily prepared by PVD methods (thermal or electron beam evaporation, and sputtering), electrodeposition, or electroless deposition. PVD and electrodeposition can generate thin films of a wide range of metals (including gold, silver, copper, palladium, platinum, and nickel) and alloys.

a.

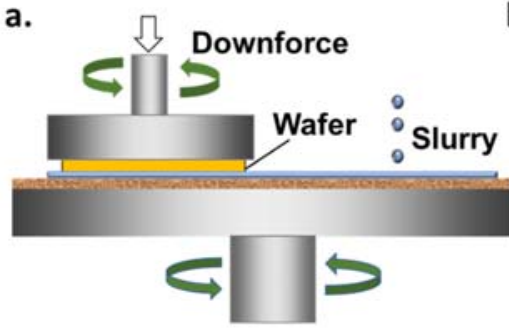

c.

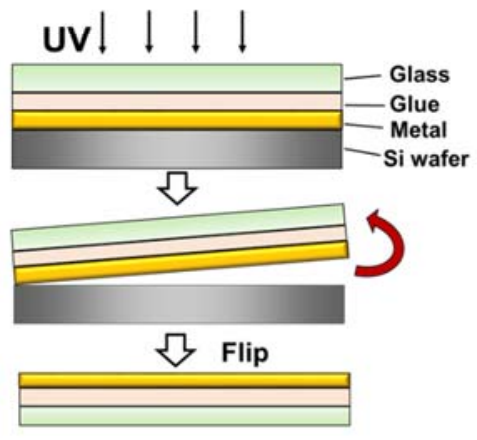

b.

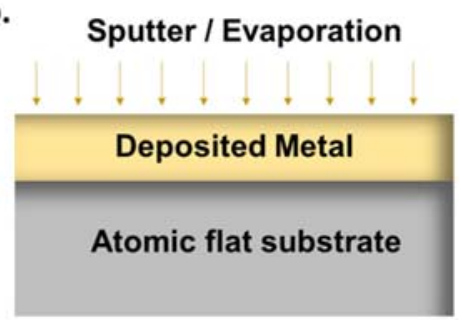

d.

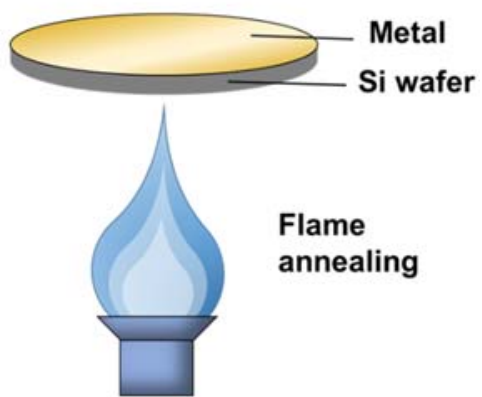

Figure 6. Schematic illustration of four different substrate preparation processes (a) chemical mechanical polishing; (b) PVD; (c) template stripping; (d) annealing-assisted template stripping.

\subsection{Substrates Roughness}

All these preparation methods aim at producing smooth surfaces with the combination of mechanical and/or chemical forces. The substrate's root mean square (RMS) roughness observed from these methods 
ranges from 0.3 to $15 \mathrm{~nm}$. Table 1 summarizes RMS roughness of all substrates prepared by corresponding methods. The self-assembly process of alkanethiolates on metal depends on a number of parameters that include; the chain length, degree of order, and topography/roughness of the substrate. Therefore, the structure and properties of SAMs significantly depend on the substrate.

Table 1. Summary of substrates root mean square (RMS) roughness fabricated by different prepared methods.

\begin{tabular}{cccc}
\hline Methods & Metal & RMS Roughness (nm) & Reference \\
\hline & $\mathrm{Ag}$ & $5.13 \pm 0.22$ & {$[25]$} \\
& $\mathrm{Au}$ & 2.03 & {$[50]$} \\
PVD & $\mathrm{Au}$ & $2.27 \pm 0.16$ & {$[25]$} \\
& $\mathrm{Au}$ & 15 & {$[23]$} \\
& $\mathrm{Pd}$ & 0.8 & {$[12]$} \\
\hline \multirow{4}{*}{ Chemical mechanical polishing } & $\mathrm{Ag}$ & $1.27 \pm 0.16$ & {$[51]$} \\
& $\mathrm{Ag}$ & $<5$ & {$[52]$} \\
& $\mathrm{Au}$ & $0.38 \pm 0.05$ & {$[49]$} \\
\hline & $\mathrm{Ag}$ & $0.6 \pm 0.04$ & {$[25]$} \\
& $\mathrm{Au}$ & 0.6 & {$[32]$} \\
Template stripping & $\mathrm{Au}$ & $0.36 \pm 0.01$ & {$[25]$} \\
& $\mathrm{Au}$ & $\sim 0.3-0.7$ & {$[26]$} \\
\hline Annealing-assisted template & $\mathrm{Au}$ & $0.9 \pm 0.2$ & {$[24]$} \\
stripping & $\mathrm{Au}$ & $1.97 \pm 0.12$ & {$[53]$} \\
\hline
\end{tabular}

Template stripping can generate surfaces with roughness $<1 \mathrm{~nm}[25]$, in which technique a glass slide or other solid support is glued to the exposed surface of a metal film deposited on silicon wafer, and then the metal film is peeled from the wafer to expose the surface that had been in direct contact with the wafer. Chen et al. (2015) reported a new method, referred to as "remote mechanical annealing (ReMA)" to fabricate ultra-flat Au surface with RMS roughness as low as $0.2 \mathrm{~nm}$ [26].

\subsection{Effect of Grain Size and/or Substrate Morphology}

SAMs structure is not only dependent on the substrates roughness RMS, but also on its morphology [54]. The grain sizes on metal thin film surface can vary substantially, depending on the experimental methods and conditions used in their formation. Semaltianos and Wilson have shown that the average size of deposited gold grains increases with changing the temperature of the substrate from room temperature to $400{ }^{\circ} \mathrm{C}$ during thermal deposition [55]. Godin et al. reported that both the kinetics of SAM formation and the resulting SAM structure were strongly dependent on the surface structure of the underlying gold substrate, with surfaces having large, flat grains produces high-quality self-assembled monolayers [24]. SAMs form ordered structure preferably on a grain but are more liquid-like and defective at grain boundaries [11]. If surface with small grains contain large numbers of grain boundaries, SAMs cannot pack well on it, and surfaces with large roughness RMS gives poorly packed SAMs.

Jiang et al. [32] controlled the topography of the bottom electrode (substrate) in self-assembled monolayer (SAM)-based junctions. Controlling of the number of grains per unit area, the width of the grain boundaries, and the roughness improved the yield of working junctions from $60 \%$ to near $100 \%$. 
In SAM studies and applications, metal surfaces fabricated by template-stripped surfaces are dominated by large smoother grains on which SAMs can pack well, and containing only small areas of exposed grain boundaries, compared to commonly used direct deposition methods,. Thus, for molecular diodes to perform well, it is crucial to minimize leakage currents by limiting the amount of exposed grain boundaries [56].

\section{Effect of Substrate on Wetting: Resolution of the Whitesides and Porter Discrepancy}

\subsection{Odd-Even Effect in the Hydrophobicity of n-Alkanethiolate SAMs Depends on the Roughness of the Substrate}

An ideal SAM on an atomically flat surface consists of assembled molecules in an all trans- extended conformation with no gauche rotation (Figure 2a), and an odd-even effect in wetting or other interface dependent properties of such an ideal SAM is expected due to the change in the orientation of the orientation of the terminal moiety relative to the surface. This orientation difference with the number of $\mathrm{CH}_{2}$ units, c, has previously been implicated as a possible origin of the odd-even effect $[18,25,41,48]$. It is observed that the orientation of the terminal moiety should invert with the change of the substrate from $\mathrm{Au}$ to Ag and vice versa, based on the known structures of SAMs on these surfaces (Figure 7a).

Newcomb et al. reported the hydrophobicity of n-alkanethiolate SAMs on two different roughness of $\mathrm{Au}$ and $\mathrm{Ag}$ substrates, which were fabricated by as-deposited $\left(\mathrm{M}^{\mathrm{AD}}\right)$ and template-stripped $\left(\mathrm{M}^{\mathrm{TS}}\right)$ methods, respectively [25]. Atomic force microscopy (AFM) analysis showed that $\mathrm{Au}^{\mathrm{TS}}$ has $\mathrm{RMS}$ roughness of $0.36 \pm 0.01 \mathrm{~nm}$ while $\mathrm{Au}^{\mathrm{AD}}$ has $\mathrm{RMS}$ roughness of $2.27 \pm 0.16 \mathrm{~nm}, \mathrm{Ag}^{\mathrm{TS}} \mathrm{RMS}$ roughness was $0.6 \pm 0.04 \mathrm{~nm}$, and $\mathrm{Ag}^{\mathrm{AD}} \mathrm{RMS}$ roughness is $5.13 \pm 0.22 \mathrm{~nm}$. They observed no zigzag oscillation in values of contact angle $(\theta \mathrm{s})$ with an increase in the molecular length (Figure $7 \mathrm{~b}$ ), but a slight and gradual increase in $\theta \mathrm{s}$ from $\mathrm{C}_{9}\left(108.1^{\circ}\right.$ of water on $\mathrm{Au}^{\mathrm{AD}}$, and $105.8^{\circ}$ of water on $\left.\mathrm{Ag}^{\mathrm{AD}}\right)$ to $\mathrm{C}_{16}\left(110.7^{\circ}\right.$ of water on $\mathrm{Au}^{\mathrm{AD}}$ and $109.3^{\circ}$ of water on $\mathrm{Ag}^{\mathrm{AD}}$ ), and the curve plateaued after $\mathrm{C}_{14}$. This increase in $\theta \mathrm{s}$ between shorter and longer molecular chains is attributed to the SAM becoming more crystalline. The odd-even effect in hydrophobicity, however, was observed only on the smooth $\mathrm{Au}^{\mathrm{TS}}$ and $\mathrm{Ag}^{\mathrm{TS}}$ substrates (Figure 7c). It is also reported that the odd-even effect inverts when the surface is changed from Au to Ag, which is due to the inversion of the orientation of the terminal moiety and, hence, the surface dipole. Therefore, we believe that the properties of the SAMs are strongly dependent on the roughness of the substrate where the SAM is formed. When the surface is rough, interfacial behavior is dominated by molecules and the odd-even effect is not observed. Figure $7 \mathrm{~d}$ shows the large difference between even-numbered SAMs $\left(\mathrm{SAM}^{\mathrm{E}}\right)$ on $\mathrm{Au}^{\mathrm{TS}}$ and $\mathrm{Ag}^{\mathrm{TS}}$, while a small difference is observed for odd-numbered $\mathrm{SAMs}\left(\mathrm{SAM}^{\mathrm{O}}\right)$, suggesting that the orientation of the molecular dipoles leads to an odd-even effect in wetting. Surface dipoles has a dominant effect in SAM hydrophobicity, and may attribute to the high $\theta$ s, relative to hydrocarbon polymers. The discrepancy between Porter's and Whitesides' work could, therefore, be due to surface roughness, surface morphology, oxidation, and adventitious contaminants, as suggested by Laibinis. Assuming that both group were diligent in their experimental work, however, suggests that the differences could be due to the nature of the surface morphologies. 


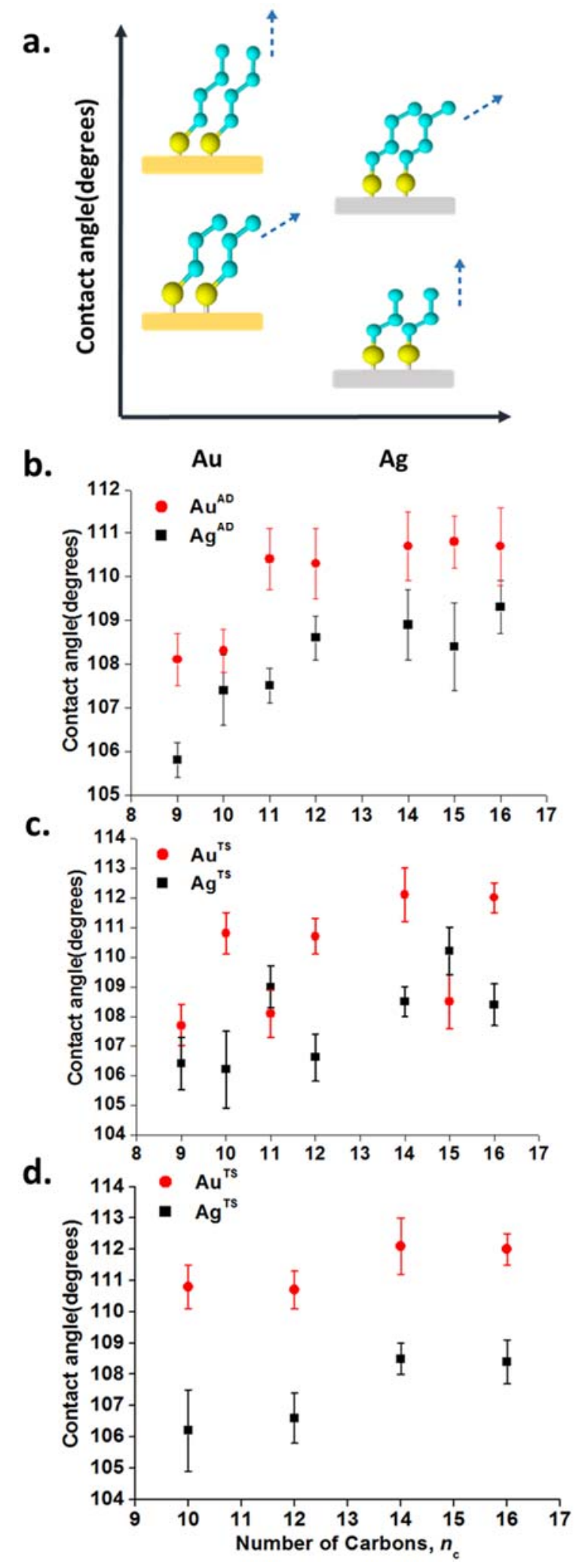

Figure 7. (a) Schematic illustration of the structural effect of the SAM on metal surfaces. Orientation of the terminal moiety inverts with the change of the substrate; $\mathrm{SAM}^{\mathrm{E}}$ on $\mathrm{Au}$ orients like $\mathrm{SAM}^{\mathrm{O}}$ on $\mathrm{Ag}$ and vice versa; (b) $\theta$ s of water on $\mathrm{n}$-alkanethiolate SAMs formed on $\mathrm{Au}^{\mathrm{AD}}$ and $\mathrm{Ag}^{\mathrm{AD}}$ substrates; (c) odd-even effects in the hydrophobicity of alkanethiolate SAMs formed on smoother $\mathrm{Au}^{\mathrm{TS}}$ and $\mathrm{Ag}^{\mathrm{TS}}$ substrates; and (d) $\theta$ s of $\mathrm{SAM}^{\mathrm{E}}$ on $\mathrm{Au}^{\mathrm{TS}}$ and $\mathrm{Ag}^{\mathrm{TS}}$ substrates show a significant difference in the values of $\theta$ s. 


\subsection{The Grain Size of the Substrate}

Wang et al. recently reported that the wetting properties of n-alkanethiolate SAMs on $\mathrm{Ag}^{\mathrm{Fe}-\mathrm{TS}}$ and $\mathrm{Au}^{\mathrm{AD}}$ substrates, surfaces with RMS roughness around $2 \mathrm{~nm}$ but completely different morphology (Figure 8a,b) [54]. Higher surface coverage was observed on $\mathrm{Ag}^{\mathrm{Fe}-\mathrm{TS}}$ than on $\mathrm{Au}^{\mathrm{AD}}$, which indicated more defects on $\mathrm{Au}^{\mathrm{AD}}$ surface due to the large grains that would offer some flat areas for ideal SAMs deposition. As expected, the wetting properties, as manifested in the odd-even effect in wetting with hexadecane inverts when the substrate is Au vs. Ag-similar observations were made when the smooth substrates were used to study hydrophobicity. 3D AFM profile images of the substrates indicate that the flat area of grains was not on the top (Figure 8c), but, rather, surface asperities would dominate (Figure 8d). The defects dominating the $\mathrm{Au}^{\mathrm{AD}}$ surface caused inversion in wetting properties of SAMs compared to the previously reported $\mathrm{Au}^{\mathrm{TS}}$, which indicated that surface morphology is critical in understanding interfacial properties of SAMs.

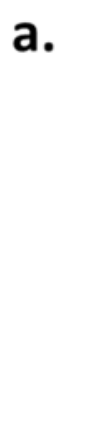

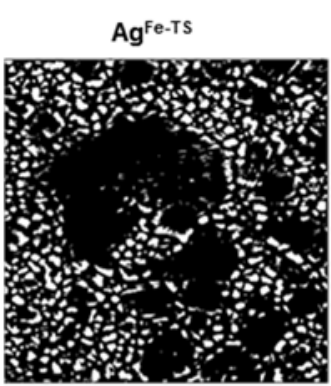

RMS: $2.09 \pm 0.39 \mathrm{~nm}$

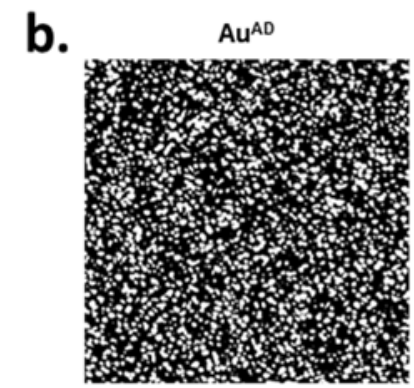

RMS: $2.27 \pm 0.16 \mathrm{~nm}$

C.

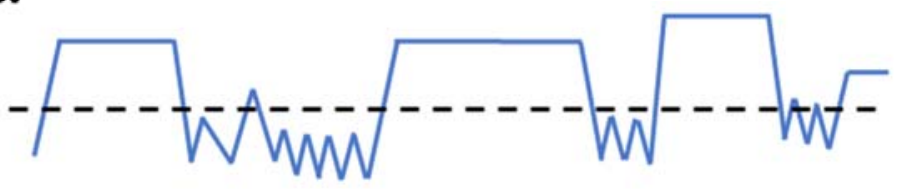

d.

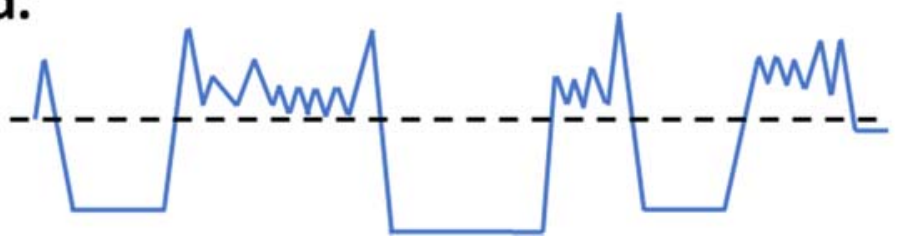

Figure 8. (a) Images of grains on $\mathrm{Ag}^{\mathrm{Fe}-\mathrm{TS}}$ substrate; (b) Images of grains on $\mathrm{Au}^{\mathrm{AD}}$ substrate; (c) Schematic illustration of the substrates from previous studies; (d) Schematic illustration of the substrates of Wang et al.'s work.

\subsection{The Surface Roughness Limit on the Odd-Even Effect in Hydrophobicity}

Chen et al. prepared smoother $\mathrm{Au}^{\mathrm{M}-\mathrm{TS}}$ surfaces using remote mechanical annealing (ReMA) methods, compared to normal template stripped $\mathrm{Au}^{\mathrm{TS}}$, and showed that $\mathrm{Au}^{\mathrm{Pd}-\mathrm{TS}}, \mathrm{Au}^{\mathrm{Ti}-\mathrm{TS}}$, and $\mathrm{Au}^{\mathrm{Fe}-\mathrm{TS}}$ surfaces have average RMS roughnesses of $0.35 \pm 0.03,0.25 \pm 0.07$, and $0.21 \pm 0.03 \mathrm{~nm}$, respectively [26]. $\mathrm{Au}^{\mathrm{TS}}$ had comparatively larger grains and greater RMS roughness $(0.4 \pm 0.06 \mathrm{~nm})$ than $\mathrm{Au}^{\mathrm{M}-\mathrm{TS}}$. The lowest surface roughness of $\mathrm{Au}^{\mathrm{Zn}-\mathrm{TS}}$, among all the samples, almost approaches a $\mathrm{C}-\mathrm{C}$ bond length. There is an observable odd-even effect in hydrophobicity of n-alkanethiolate SAMs on all samples. 
In Figure 9, the two series give $\theta_{\mathrm{s}}^{\mathrm{E}}=107.0^{\circ}\left(\mathrm{SAM}^{\mathrm{E}}\right)$ and $\theta_{\mathrm{s}}^{\mathrm{O}}=104.1^{\circ}\left(\mathrm{SAM}^{\mathrm{O}}\right)$ on a hypothetical atomically smooth surface with no defects (i.e., RMS roughness $=0$ ) - that is, when the linear fits are extrapolated to the $Y$-axis, which is. The difference in hydrophobicity of $\mathrm{SAM}^{\mathrm{O}}$ and $\mathrm{SAM}^{\mathrm{E}}$ when RMS roughness $=0$ ( $Y$-axis intercept $)$ suggests an average $\Delta \theta_{\mathrm{s}} \mid$ even-odd $\mid \approx 3^{\circ}$, which indicated the ultimate contribution of the odd-even effect to the hydrophobicity of n-alkanethiolate SAMs is $3^{\circ}$. Meanwhile, the substrate RMS roughness was close to $1 \mathrm{~nm}, \Delta \theta_{\mathrm{s}} \mid$ even-odd $\mid \approx 0^{\circ}$ which means that the odd-even effect in hydrophobicity cannot be observed. This study, therefore, gave the maximum contribution of the odd-even effect in differences in contact angles, and also indicated that the odd-even effect is limited by surface roughness. This study, and based on the state-of-the-art in surface fabrication 25 years ago, supports the data reported by Whitesides and co-workers, and it is surprising that Porter observed an odd-even effect, especially with shorter n-alkanethiolates.

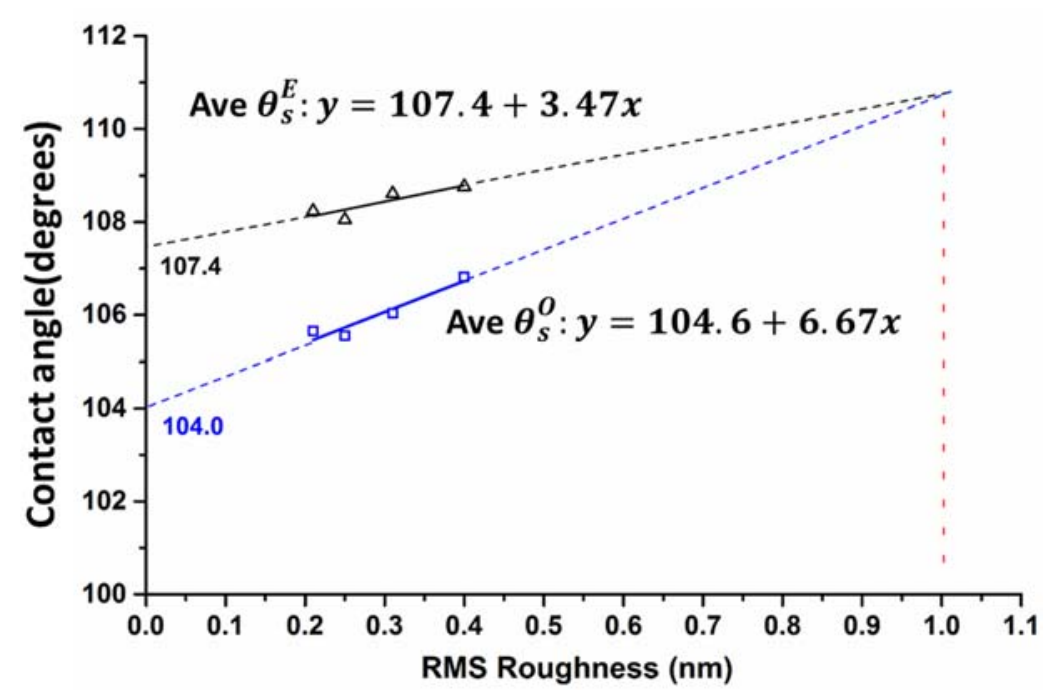

Figure 9. Comparing the substrate roughness with the average contact angles measured on odd and even SAMs. Dashed lines are fitted lines showing the effect of surface roughness on the odd-even effect.

\section{Summary}

This review discusses the odd-even effect in wetting and other interfacial properties of SAMs, and especially emphasizes the Porter-Whitesides discrepancy, bringing to forefront an understanding of some fundamental properties of n-alkanethiolate SAMs. To this end, we must emphasis that:

(i) The origin of the Porter-Whitesides Discrepancy is probably a manifestation of the effect of surface roughness and/or morphology on the odd-even effect. Porter's data [21] showed odd-even effect; however, the oscillation in the values of contact angle was inverted compared to what we later observed $[25,26,54]$.

(ii) There is a need to fully characterize surface morphology for studies reporting interfacial properties of SAMs. Despite the original Whitesides-Porter discrepancy, there are many papers that report data involving surfaces modification without the requisite report on the nature of the surfaces being used. The prediction of the possibility of a theoretical limit of substrate roughness RMS $(\sim 1 \mathrm{~nm})$, beyond which the odd-even effect in wetting is absent, further emphasizes the need for at least a report on the surface roughness if comparative analysis, and, hence, generalization, are going to be realized. 
(iii) The wetting behavior of SAMs depended on the surface morphology with the odd-even effect, as captured in the static contact angle, having a maximum limit $\left(3^{\circ}\right)$ and a minimum $\left(0^{\circ}\right.$, i.e., no odd-even effect). This values acts as a guideline in the further development or engineering of interfacial properties of SAMs.

\section{Acknowledgments}

This work was supported by Iowa State University through startup funds. M.T. acknowledges support through a Black and Veatch Building a World of Difference Faculty Fellowship from Iowa State University. M.T. and J.C. were supported in part by a Catron fellowship from the Engineering Research Institute.

\section{Conflicts of Interest}

The authors declare no conflict of interest.

\section{References}

1. Franklin, B.; Brownrigg, W.; Farish, M. Of the stilling of waves by means of oil. Extracted from sundry letters between Benjamin Franklin, LL. D.F.R.S. William Brownrigg, M.D.F.R.S. and the reverend Mr. Farish. Phil. Trans. 1774, 64, 445-460.

2. Bigelow, W.C.; Pickett, D.L.; Zisman, W.A. Oleophobic monolayers: I. Films adsorbed from solution in non-polar liquids. J. Colloid Sci. 1946, 1, 513-538.

3. Kuhn, H.; Möbius, D. Systems of monomolecular layers-Assembling and physico-chemical behavior. Angew. Chem. Int. Ed. 1971, 10, 620-637.

4. Nuzzo, R.G.; Allara, D.L. Adsorption of bifunctional organic disulfides on gold surfaces. J. Amer. Chem. Soc. 1983, 105, 4481-4483.

5. Ulman, A. Formation and structure of self-assembled monolayers. Chem. Rev. 1996, 96, 1533-1554.

6. Atre, S.V.; Liedberg, B.; Allara, D.L. Chain length dependence of the structure and wetting properties in binary composition monolayers of $\mathrm{OH}$-and $\mathrm{CH}_{3}$-terminated alkanethiolates on gold. Langmuir 1995, 11, 3882-3893.

7. Flynn, N.T.; Tran, T.N.T.; Cima, M.J.; Langer, R. Long-term stability of self-assembled monolayers in biological media. Langmuir 2003, 19, 10909-10915.

8. Graupe, M.; Takenaga, M.; Koini, T.; Colorado, R., Jr.; Lee, T.R. Oriented surface dipoles strongly influence interfacial wettabilities. J. Amer. Chem. Soc. 1999, 121, 3222-3223.

9. Kudelski, A. Structures of monolayers formed from different HS- $\left(\mathrm{CH}_{2}\right)_{2}-\mathrm{x}$ thiols on gold, silver and copper: Comparitive studies by surface-enhanced raman scattering. J. Raman Spectrosc. 2003, 34, 853-862.

10. Laibinis, P.E.; Whitesides, G.M.; Allara, D.L.; Tao, Y.T.; Parikh, A.N.; Nuzzo, R.G. Comparison of the structures and wetting properties of self-assembled monolayers of n-alkanethiols on the coinage metal surfaces, copper, silver, and gold. J. Amer. Chem. Soc. 1991, 113, 7152-7167.

11. Love, J.C.; Estroff, L.A.; Kriebel, J.K.; Nuzzo, R.G.; Whitesides, G.M. Self-assembled monolayers of thiolates on metals as a form of nanotechnology. Chem. Rev. 2005, 105, 1103-1169. 
12. Love, J.C.; Wolfe, D.B.; Haasch, R.; Chabinyc, M.L.; Paul, K.E.; Whitesides, G.M.; Nuzzo, R.G. Formation and structure of self-assembled monolayers of alkanethiolates on palladium. J. Amer. Chem. Soc. 2003, 125, 2597-2609.

13. Rusu, P.C.; Giovannetti, G.; Brocks, G. Dipole formation at interfaces of alkanethiolate self-assembled monolayers and Ag (111). J. Phys. Chem. C 2007, 111, 14448-14456.

14. Tao, F.; Bernasek, S.L. Understanding odd-even effects in organic self-assembled monolayers. Chem. Rev. 2007, 107, 1408-1453.

15. Whitesides, G.M.; Grzybowski, B. Self-assembly at all scales. Science 2002, 295, 2418-2421.

16. Wong, S.-S.; Takano, H.; Porter, M.D. Mapping orientation differences of terminal functional groups by friction force microscopy. Anal. Chem. 1998, 70, 5209-5212.

17. Stoliar, P.; Kshirsagar, R.; Massi, M.; Annibale, P.; Albonetti, C.; de Leeuw, D.M.; Biscarini, F. Charge injection across self-assembly monolayers in organic field-effect transistors: Odd-even effects. J. Amer. Chem. Soc. 2007, 129, 6477-6484.

18. Thuo, M.M.; Reus, W.F.; Nijhuis, C.A.; Barber, J.R.; Kim, C.; Schulz, M.D.; Whitesides, G.M. Odd-even effects in charge transport across self-assembled monolayers. J. Amer. Chem. Soc. 2011, 133, 2962-2975.

19. Baghbanzadeh, M.; Simeone, F.C.; Bowers, C.M.; Liao, K.-C.; Thuo, M.; Baghbanzadeh, M.; Miller, M.S.; Carmichael, T.B.; Whitesides, G.M. Odd-even effects in charge transport across n-alkanethiolate-based sams. J. Amer. Chem. Soc. 2014, 136, 16919-16925.

20. Dubi, Y. Transport through self-assembled monolayer molecular junctions: Role of in-plane dephasing. J. Phys. Chem. C 2014, 118, 21119-21127.

21. Walczak, M.M.; Chung, C.; Stole, S.M.; Widrig, C.A.; Porter, M.D. Structure and interfacial properties of spontaneously adsorbed n-alkanethiolate monolayers on evaporated silver surfaces. J. Amer. Chem. Soc. 1991, 113, 2370-2378.

22. Biebuyck, H.A.; Bain, C.D.; Whitesides, G.M. Comparison of organic monolayers on polycrystalline gold spontaneously assembled from solutions containing dialkyl disulfides or alkanethiols. Langmuir 1994, 10, 1825-1831.

23. Yang, J.; Han, J.; Isaacson, K.; Kwok, D.Y. Effects of surface defects, polycrystallinity, and nanostructure of self-assembled monolayers for octadecanethiol adsorbed onto au on wetting and its surface energetic interpretation. Langmuir 2003, 19, 9231-9238.

24. Godin, M.; Williams, P.J.; Tabard-Cossa, V.; Laroche, O.; Beaulieu, L.; Lennox, R.B.; Grütter, P. Surface stress, kinetics, and structure of alkanethiol self-assembled monolayers. Langmuir 2004, 20, 7090-7096.

25. Newcomb, L.B.; Tevis, I.D.; Atkinson, M.B.; Gathiaka, S.M.; Luna, R.E.; Thuo, M. Odd-even effect in the hydrophobicity of n-alkanethiolate self-assembled monolayers depends upon the roughness of the substrate and the orientation of the terminal moiety. Langmuir 2014, 30, 11985-11992.

26. Chen, J.; Wang, Z.; Oyola-Reynoso, S.; Gathiaka, S.M.; Thuo, M. Limits to the effect of substrate roughness or smoothness on the odd-even effect in wetting properties of n-alkanethiolate monolayers. Langmuir 2015, 31, 7047-7054.

27. Lee, S.; Puck, A.; Graupe, M.; Colorado, R., Jr.; Shon, Y.-S.; Lee, T.R.; Perry, S.S. Structure, wettability, and frictional properties of phenyl-terminated self-assembled monolayers on gold. Langmuir 2001, 17, 7364-7370. 
28. Srivastava, P.; Chapman, W.G.; Laibinis, P.E. Odd-even variations in the wettability of n-alkanethiolate monolayers on gold by water and hexadecane: A molecular dynamics simulation study. Langmuir 2005, 21, 12171-12178.

29. Rong, H.-T.; Frey, S.; Yang, Y.-J.; Zharnikov, M.; Buck, M.; Wühn, M.; Wöll, C.; Helmchen, G. On the importance of the headgroup substrate bond in thiol monolayers: A study of biphenyl-based thiols on gold and silver. Langmuir 2001, 17, 1582-1593.

30. Thuo, M.M.; Reus, W.F.; Simeone, F.C.; Kim, C.; Schulz, M.D.; Yoon, H.J.; Whitesides, G.M. Replacing- $\mathrm{CH}_{2} \mathrm{CH}_{2}$-with-CONH-does not significantly change rates of charge transport through AgTS-SAM//Ga $\mathrm{O}_{3}$ /egain junctions. J. Am. Chem. Soc. 2012, 134, 10876-10884.

31. Nurbawono, A.; Liu, S.; Nijhuis, C.A.; Zhang, C. Odd-even effects in charge transport through self-assembled monolayer of alkanethiolates. J. Phys. Chem. C 2015, 119, 5657-5662.

32. Jiang, L.; Sangeeth, C.S.; Nijhuis, C.A. The origin of the odd-even effect in the tunneling rates across egain junctions with self-assembled monolayers (SAMs) of n-alkanethiolates. J. Amer. Chem. Soc. 2015, 137, 10659-10667.

33. Nerngchamnong, N.; Yuan, L.; Qi, D.-C.; Li, J.; Thompson, D.; Nijhuis, C.A. The role of van der waals forces in the performance of molecular diodes. Nat. nanotechnol. 2013, 8, 113-118.

34. Yuan, L.; Thompson, D.; Cao, L.; Nerngchangnong, N.; Nijhuis, C.A. One carbon matters: The origin and reversal of odd-even effects in molecular diodes with self-assembled monolayers of ferrocenyl-alkanethiolates. J. Phys. Chem. C 2015, 119, 17910-17919.

35. Kornilovitch, P.; Bratkovsky, A.; Williams, R.S. Current rectification by molecules with asymmetric tunneling barriers. Phys. Rev. B 2002, 66, 165436.

36. Nijhuis, C.A.; Reus, W.F.; Whitesides, G.M. Molecular rectification in metal-SAM-metal oxide-metal junctions. J. Am. Chem. Soc. 2009, 131, 17814-17827.

37. Nijhuis, C.A.; Reus, W.F.; Barber, J.R.; Dickey, M.D.; Whitesides, G.M. Charge transport and rectification in arrays of sam-based tunneling junctions. Nano lett. 2010, 10, 3611-3619.

38. Nijhuis, C.A.; Reus, W.F.; Whitesides, G.M. Mechanism of rectification in tunneling junctions based on molecules with asymmetric potential drops. J. Amer. Chem. Soc. 2010, 132, 18386-18401.

39. Lin, S.-Y.; Tsai, T.-K.; Lin, C.-M.; Chen, C.-h.; Chan, Y.-C.; Chen, H.-W. Structures of self-assembled monolayers of n-alkanoic acids on gold surfaces modified by underpotential deposition of silver and copper: Odd-even effect. Langmuir 2002, 18, 5473-5478.

40. Mikulski, P.T.; Herman, L.A.; Harrison, J.A. Odd and even model self-assembled monolayers: Links between friction and structure. Langmuir 2005, 21, 12197-12206.

41. Yang, Y.; Jamison, A.C.; Barriet, D.; Lee, T.R.; Ruths, M. Odd-even effects in the friction of self-assembled monolayers of phenyl-terminated alkanethiols in contacts of different adhesion strengths. J. Adhes. Sci. Technol. 2010, 24, 2511-2529.

42. Ramin, L.; Jabbarzadeh, A. Effect of compression on self-assembled monolayers: A molecular dynamics study. Modell. Simul. Mater. Sci. Eng. 2012, 20, 085010.

43. Ramin, L.; Jabbarzadeh, A. Effect of load on structural and frictional properties of alkanethiol self-assembled monolayers on gold: Some odd-even effects. Langmuir 2012, 28, 4102-4112.

44. Ramin, L.; Jabbarzadeh, A. Effect of water on structural and frictional properties of self assembled monolayers. Langmuir 2013, 29, 13367-13378. 
45. Heister, K.; Rong, H.-T.; Buck, M.; Zharnikov, M.; Grunze, M.; Johansson, L. Odd-even effects at the s-metal interface and in the aromatic matrix of biphenyl-substituted alkanethiol self-assembled monolayers. J. Phys. Chem. B 2001, 105, 6888-6894.

46. Shaporenko, A.; Brunnbauer, M.; Terfort, A.; Grunze, M.; Zharnikov, M. Structural forces in self-assembled monolayers: Terphenyl-substituted alkanethiols on noble metal substrates. J. Phys. Chem. B 2004, 108, 14462-14469.

47. Azzam, W.; Bashir, A.; Terfort, A.; Strunskus, T.; Wöll, C. Combined stm and ftir characterization of terphenylalkanethiol monolayers on $\mathrm{Au}$ (111): Effect of alkyl chain length and deposition temperature. Langmuir 2006, 22, 3647-3655.

48. Ramin, L.; Jabbarzadeh, A. Odd-even effects on the structure, stability, and phase transition of alkanethiol self-assembled monolayers. Langmuir 2011, 27, 9748-9759.

49. Miller, M.S.; Ferrato, M.-A.; Niec, A.; Biesinger, M.C.; Carmichael, T.B. Ultrasmooth gold surfaces prepared by chemical mechanical polishing for applications in nanoscience. Langmuir 2014, 30, 14171-14178.

50. Hong, Y.-K.; Yu, H.; Lee, T.G.; Lee, N.; Bahng, J.H.; Song, N.W.; Chegal, W.; Shon, H.K.; Koo, J.-Y. Highly-ordered self-assembled monolayer of alkanethiol on thermally annealed polycrystalline gold films. Chem. Phys. 2014, 428, 105-110.

51. Tiani, D.J.; Yoo, H.; Mudalige, A.; Pemberton, J.E. Interfacial structure in thin water layers formed by forced dewetting on self-assembled monolayers of $\omega$-terminated alkanethiols on Ag. Langmuir 2008, 24, 13483-13489.

52. Wang, Z.; Nania, S.L.; Shaw, S.K. Structure of aqueous water films on textured-OH-terminated self-assembled monolayers. Langmuir 2015, 31, 2382-2389.

53. Banner, L.T.; Richter, A.; Pinkhassik, E. Pinhole-free large-grained atomically smooth Au (111) substrates prepared by flame-annealed template stripping. Surf. Interface Anal. 2009, 41, 49-55.

54. Wang, Z.; Chen, J.; Gathiaka, S.M.; Oyola-Reynoso, S.; Thuo, M. Wettability of n-alkanethiolate self-assembled monolayers correlates more with surface roughness than with the presence of large grains on the substrate. Langmuir submitted.

55. Semaltianos, N.G.; Wilson, E.G. Investigation of the surface morphology of thermally evaporated thin gold films on mica, glass, silicon and calcium fluoride substrates by scanning tunneling microscopy. Thin Solid Films 2000, 366, 111-116.

56. Yuan, L.; Jiang, L.; Thompson, D.; Nijhuis, C.A. On the remarkable role of surface topography of the bottom electrodes in blocking leakage currents in molecular diodes. J. Amer. Chem. Soc. 2014, $136,6554-6557$.

(C) 2015 by the authors; licensee MDPI, Basel, Switzerland. This article is an open access article distributed under the terms and conditions of the Creative Commons Attribution license (http://creativecommons.org/licenses/by/4.0/). 